\title{
The Emotional Impact of Social Media in Higher Education
}

\author{
Darren Iwamoto ${ }^{1} \&$ Hans Chun $^{1}$ \\ ${ }^{1}$ School of Education and Behavioral Sciences, Chaminade University, Honolulu, United States \\ Correspondence: Darren Iwamoto, School of Education and Behavioral Sciences, Chaminade University, Honolulu, \\ HI, 96816, United States.
}

Received: December 29, 2019

Accepted: February 5, $2020 \quad$ Online Published: February 6, 2020

doi:10.5430/ijhe.v9n2p239

URL: https://doi.org/10.5430/ijhe.v9n2p239

\begin{abstract}
College and university students have been observed increasing their usage of social media applications as it has become central to everyday life. Students can use different forms of social media to connect, share, and view a myriad of content. When influenced by posts, social media can have a significant impact on their lives. Social media can be a form of social support, but it can also have a negative effect on mental health. With the increase in use, social media can provoke individuals to begin self-comparing or gain an unrealistic expectation of themselves and other individuals. This can lead to lower self-esteem, self-confidence, and self-worth. This exploratory study attempts to determine the relationship between social media use and its impact on depression, anxiety, and stress amongst students in higher education.
\end{abstract}

Keywords: social media, stress, anxiety, depression, higher education, social connectedness

\section{Introduction}

Social media usage has increased significantly globally. Recent studies on social media usage report about 3 billion people globally are currently using social media. The increase in the population of social media usage has also increased the amount of time spent on social platforms, with statistics indicating that people spend an average of 2 hours a day on different social media platforms, sharing messages and pictures, tweeting, updating status, liking, and commenting on different social updates (Abbott, 2017). Social media is also viewed as a form of social support for the majority of college and university students, but it can also have an adverse effect on their mental health, especially for those who already have high levels of anxiety and depression (Drouin, Reining, Flanagan, Carpenter \& Toscos, 2018). Charoensukmongkol (2018) supported this finding by determining that the global population could be risking a great deal of its mental health and well-being through social use. Tang, Wang, and Norman (2013) found that the process of sharing, tweeting, liking, texting, and undertaking other activities common in social media have been linked to an increase in stress. Therefore, Weng and Menczer (2015) argue that the major negative social impact of increased social media usage is that it has become a serious source of stress, since people often share all manner of feeds, stories, and comments that range from politics and economics, to social and personal issues of concern. Subsequently, an individual spending an average of 2 hours on social media platforms will end up collecting a lot of negative news, stories, and information, which impacts their overall stress level (Ley, Ogonowski, Hess, Reichling, Wan \& Wulf, 2014).

According to Hales (2009), a person's college years have been deemed as one of the most stressful periods of a person's life. Stress can impact our behavior and memory; more specifically, academic performance (Yerkes \& Dodson, 1908). Initially, as observed by Charoensukmongkol (2018), individuals used social media as a platform for relieving stress, where they could meet with friends to chat their stresses and concerns away. However, while social media initially acted as a coping mechanism for stress, the continued learning of other people's stress resulted in those individuals to develop stress over time (Fleck \& Johnson-Migalski, 2015). Additionally, social media platforms remain a foremost source of mood change for most people, whereas an individual could be passively lurking around a social media platform, but end up with a changed mood based on the nature of the content being viewed (Chukwuere \& Chukwuere, 2017). Subsequently, bad and low moods are easily spread amongst people using social media platforms. This is proving to be problematic as college and university students have been observed increasing their usage of social media applications as it has become central to everyday life.

Social media has become a vital and integral part of peoples' lives in today's digital age. Although social media provides significant benefits in many aspects, it is crucial to understand the negative impacts that it causes as well 
(Sriwilai \& Charoensukmongkol, 2016). Anxiety and depression are psychological states that a person can experience where there is a stressor(s) present. When stress is present, our natural flight-fight-freeze response is activated that when prolonged could result in organize changes in our brain that would affect our cognitive, physical, emotional, and behavioral abilities (Santee, 2013). Aalbers, McNally, Heeren, de Wit, and Fried (2018) found that those who spent more time passively using social media experienced higher levels of loneliness, depressed mood, hopelessness, and feeling inferior. Yet, Halston, Iwamoto, Junker, and Chun (2019) found that the level of social interaction when using social media platforms were too superficial to influence a person's mood positively. Subsequently, social media platforms were found to be to have no relationship with one's feeling of deep and meaningful social connectedness.

Sriwilai \& Charoensukmongkol (2016) found that those "who are addicted to social media may spend most of their time on their social media activities in order to help them forget about the problem that they are experiencing instead of trying to think about how to face the said problem" (p.433). Emotion-focused coping does not provide adequate coping, as it only allows individuals to divert their attention from stress temporarily (Chang, 2012). The challenge is that social media offers one to be exposed to a number of exciting activities and happenings, especially for the younger generation. This may attract and keep them logged into different social media platforms for hours just enjoying their time away. This typically results in lower productivity, lower academic performance, and dependency for constant stimulation (Alahmar, 2016).

Furthermore, there is also another dimension of social media use that has been found to increase social anxiety in some individuals. According to Zareen, Karim, and Khan (2016), social media use has increased anxiety among the world populations, with social media users often sharing alarming and disturbing stories that might end up as true or fake news, which impacts society through increasing the feelings of worry and restlessness. Tang, Wang, and Norman (2013) established that individuals who read negative, alarming, or highly negative graphic news experienced problems sleeping and suffered from bad dreams and nightmares. Social media platforms remain important platforms for connecting people with their friends, families, and the world around them (Rad, Jalali, \& Rahmandad, 2018). However, when the happenings spreading in social media are mainly negative or produce feelings of jealousy or envy, levels of stress, anxiety, and depression tend to increase (Iwamoto \& Chun, 2019).

Students can use different forms of social media to connect, share, and view a myriad of content. When influenced by posts, social media can have a significant impact on their lives. With the increase in use, social media can provoke individuals to begin self-comparing or gain an unrealistic expectation of themselves and other individuals. This can lead to lower self-esteem, self-confidence, and self-worth. This exploratory study attempts to determine the relationship between social media use and its impact on stress, anxiety, and depression amongst students in higher education. This is a follow-up study to the findings from Iwamoto and Chun (2019) Stress, Anxiety, and Depression: An Analysis of 21st Century Higher Education Students that recommended a deeper analysis into the relationship between social media usage and emotional well-being.

\section{Method}

The Institutional Review Board (IRB) approved this exploratory study focused on the relationship between stress, anxiety, and depression, and social media usage. The purpose of this study was to follow-up on the findings observed in the study by Iwamoto and Chun (2019): Stress, Anxiety, and Depression: An Analysis of 21st Century Higher Education Students. As relationship issues were a common theme in that study, questions regarding social contact in higher education were the motivation of this inquiry. The DASS-21 was selected again as the quantitative instrument due to its relatively high reliability (range of coefficient- $\alpha=.82-.97$ ) and validity (concurrent validity $r=.40-.65$ ) in assessing stress, anxiety, and depression (Osman, Wong, Bagge, Freedenthal, Gutierrez \& Lozano, 2012); furthermore, the DASS-21 is relatively short, and it was the same instrument used in the previous study by Iwamoto and Chun.

A convenience sample was used for this study. Participants were students in the classes of participating faculty. Surveys were distributed to 181 undergraduate students at a university located in the Pacific about a month into the fall semester to attempt to rule out confounding variables such as homesickness, large projects, and midterms.

All recruited individuals were briefed on the study and then provided a hard copy of the informed consent form to sign. Students were assured that non-participation would not affect their grade for the class in any way. The voluntary nature of this study was stressed, and the threat of coercion was minimized. Since a convenience sample was used, diversity and equity could not be assured. The sample consisted of 181 multi-disciplinary undergraduate students, 58 first-year students, 34 sophomores, 38 juniors, 47 seniors, and 4 unknowns. Demographically, the sample consisted of $69 \%$ females, $30 \%$ males, $1 \%$ unknown (did not report), 2\% African-American, $12 \%$ mixed, $29 \%$ 
Native Hawaiian/Part-Hawaiian and Pacific Islander, 16\% Caucasian, 3\% Asian, 7\% Hispanic, 1\% Native American, and $1 \%$ unknown.

Outcomes were measured using the DASS-21 and a constructed questionnaire by the authors asking participants about their social media usage. This constructed questionnaire was reviewed by experts in the field prior to its use. The results from the DASS-21 was scored using the DASS-21 Guide. An analysis of the questionnaire utilized the analysis of descriptive statistics, independent T-Test, one-way ANOVA, and the Pearson correlation coefficient to determine significant mean differences and relationships between variables.

\section{Results}

Analysis of the DASS-21 and questionnaire are shown below in Tables 1 through 26. The data shown in the tables were the significant findings.

Table 1. Descriptive Statistics - Anxiety and Hours of Use on Social Media

\begin{tabular}{cccc}
\hline Variables & Mean & Std. Deviation & $N$ \\
\hline Anxiety & 4.98 & 3.92 & 181 \\
Hours of Use & 8.74 & 8.14 & 172
\end{tabular}

Table 2. Relationship Between Anxiety and Hours of Use on Social Media

\begin{tabular}{cccc}
\hline Variables & Statistic & Anxiety & Hours of Use \\
\hline Anxiety & Pearson Correlation & 1 & $.199^{* *}$ \\
& Sig. (2 tailed) & & .009 \\
& $\mathrm{~N}$ & 181 & 172 \\
Hours of Use & Pearson Correlation & $.199^{* *}$ & 1 \\
& Sig. (2 tailed) & .009 & 172 \\
& $\mathrm{~N}$ & 172 & \\
\hline
\end{tabular}

** Correlation is significant at the .01 level (2-tailed).

As shown in Table 1 and Table 2, there was a strong positive correlation between anxiety $(M=4.98, S D=3.92)$ and hours of use $(M=8.74, S D=8.14), r=.199, p=\leq .01, n=172$.

Table 3. Descriptive Statistics - Stress and Hours of Use on Social Media

\begin{tabular}{cccc}
\hline Variables & Mean & Std. Deviation & $N$ \\
\hline Hours of Use & 8.74 & 8.14 & 172 \\
Stress & 6.72 & 4.37 & 181
\end{tabular}

Table 4. Relationship Between Stress and Hours of Use on Social Media

\begin{tabular}{cccc}
\hline Variables & Statistic & Stress & Hours of Use \\
\hline Hours of Use & Pearson Correlation & 1 & $.204^{* *}$ \\
& Sig. (2 tailed) & & .007 \\
Stress & $\mathrm{N}$ & 172 & 172 \\
& Pearson Correlation & $.204^{* *}$ & 1 \\
& Sig. (2 tailed) & .007 & 181 \\
\hline
\end{tabular}

** Correlation is significant at the .01 level (2-tailed).

As shown in Table 3 and Table 4, there was a strong positive correlation between stress $(M=6.72, S D=4.37)$ and hours of use $(M=8.74, S D=8.14), r=.204, p=\leq .01, n=172$. 
Table 5. Descriptive Statistics - Depression and Hours of Use on Social Media

\begin{tabular}{cccc}
\hline Variables & Mean & Std. Deviation & $N$ \\
\hline Hours of Use & 8.74 & 8.14 & 172 \\
Depression & 4.87 & 4.42 & 181
\end{tabular}

Table 6. Relationship Between Depression and Hours of Use on Social Media

\begin{tabular}{cccc}
\hline Variables & Statistic & Depression & Hours of Use \\
\hline Hours of Use & Pearson Correlation & 1 & $.161^{*}$ \\
& Sig. (2 tailed) & & .034 \\
& $\mathrm{~N}$ & 172 & 172 \\
Depression & Pearson Correlation & $.161^{*}$ & 1 \\
& Sig. (2 tailed) & .034 & \\
& $\mathrm{~N}$ & 172 & 181 \\
\hline
\end{tabular}

* Correlation is significant at the .05 level (2-tailed).

As shown in Table 5 and Table 6 , there was a positive correlation between depression $(M=4.87, S D=4.42)$ and hours of use ( $M=8.74, S D=8.14), r=.161, p=\leq .05, n=172$.

Table 7. Descriptive Statistics - Depression and Facebook Use (Hours per Day)

\begin{tabular}{cccc}
\hline Variables & Mean & Std. Deviation & $N$ \\
\hline Depression & 4.87 & 4.42 & 181 \\
Facebook Use & 2.12 & 3.06 & 120
\end{tabular}

Table 8. Relationship Between Depression and Facebook Use (Hours per Day)

\begin{tabular}{cccc}
\hline Variables & Statistic & Depression & Facebook Use \\
\hline Depression & Pearson Correlation & 1 & $.266^{* *}$ \\
& Sig. (2 tailed) & & .003 \\
& $\mathrm{~N}$ & 181 & 120 \\
Facebook Use & Pearson Correlation & $.266^{* *}$ & 1 \\
& Sig. (2 tailed) & .003 & 120 \\
& $\mathrm{~N}$ & 120 & 120 \\
\hline
\end{tabular}

** Correlation is significant at the .01 level (2-tailed).

As shown in Table 7 and Table 8, there was a strong positive correlation between depression $(M=4.87, S D=4.42)$ and Facebook use $(M=2.12, S D=3.06), r=.266, p=\leq .01, n=120$.

Table 9. Descriptive Statistics - Depression and Instagram Use (Hours per Day)

\begin{tabular}{cccc}
\hline Variables & Mean & Std. Deviation & $N$ \\
\hline Depression & 4.87 & 4.42 & 181 \\
Instagram Use & 2.31 & 2.53 & 150
\end{tabular}

Table 10. Relationship Between Depression and Instagram Use (Hours per Day)

\begin{tabular}{cccc}
\hline Variables & Statistic & Depression & Instagram Use \\
\hline Depression & Pearson Correlation & 1 & $.210^{* *}$ \\
& Sig. (2 tailed) & & .010 \\
& $\mathrm{~N}$ & 181 & 150 \\
Instagram Use & Pearson Correlation & $.210^{* *}$ & 1 \\
& Sig. (2 tailed) & .010 & 150 \\
& $\mathrm{~N}$ & 150 &
\end{tabular}

** Correlation is significant at the .01 level (2-tailed). 
As shown in Table 9 and Table 10, there was a strong positive correlation between depression $(M=4.87, S D=4.42)$ and Instagram use $(M=2.31, S D=2.53), r=.210, p=\leq .01, n=150$.

Table 11. Descriptive Statistics - Depression and YouTube Use (Hours per Day)

\begin{tabular}{cccc}
\hline Variables & Mean & Std. Deviation & $N$ \\
\hline Depression & 4.87 & 4.42 & 181 \\
YouTube Use & 2.78 & 2.57 & 110 \\
\hline
\end{tabular}

Table 12. Relationship Between Depression and YouTube Use (Hours per Day)

\begin{tabular}{cccc}
\hline Variables & Statistic & Depression & YouTube Use \\
\hline Depression & Pearson Correlation & 1 & $.241^{*}$ \\
& Sig. (2 tailed) & & .011 \\
& $\mathrm{~N}$ & 181 & 110 \\
YouTube Use & Pearson Correlation & $.241^{*}$ & 1 \\
& Sig. (2 tailed) & .011 & 110 \\
& $\mathrm{~N}$ & 110 & \\
\hline
\end{tabular}

* Correlation is significant at the .05 level (2-tailed).

As shown in Table 11 and Table 12, there was a positive correlation between depression $(M=4.87, S D=4.42)$ and YouTube use ( $M=2.78, S D=2.57), r=.241, p=\leq .05, n=110$.

Table 13. Descriptive Statistics - Anxiety and Facebook Use (Hours per Day)

\begin{tabular}{cccc}
\hline Variables & Mean & Std. Deviation & $N$ \\
\hline Anxiety & 4.98 & 3.92 & 181 \\
Facebook Use & 2.12 & 3.06 & 120
\end{tabular}

Table 14. Relationship Between Anxiety and Facebook Use (Hours per Day)

\begin{tabular}{cccc}
\hline Variables & Statistic & Anxiety & Facebook Use \\
\hline Anxiety & Pearson Correlation & 1 & $.184^{*}$ \\
& Sig. (2 tailed) & & .045 \\
& $\mathrm{~N}$ & 181 & 120 \\
Facebook Use & Pearson Correlation & $.184^{*}$ & 1 \\
& Sig. (2 tailed) & .045 & 120 \\
& $\mathrm{~N}$ & 120 & \\
\hline
\end{tabular}

* Correlation is significant at the .05 level (2-tailed).

As shown in Table 13 and Table 14 , there was a positive correlation between anxiety $(M=4.98, S D=3.92)$ and Facebook use $(M=2.12, S D=3.06), r=.184, p=\leq .05, n=120$.

Table 15. Descriptive Statistics - Anxiety and Instagram Use (Hours per Day)

\begin{tabular}{cccc}
\hline Variables & Mean & Std. Deviation & $N$ \\
\hline Anxiety & 4.98 & 3.92 & 181 \\
Instagram Use & 2.31 & 2.53 & 150 \\
\hline
\end{tabular}


Table 16. Relationship Between Anxiety and Instagram Use (Hours per Day)

\begin{tabular}{cccc}
\hline Variables & Statistic & Anxiety & Instagram Use \\
\hline Anxiety & Pearson Correlation & 1 & $.178^{*}$ \\
& Sig. (2 tailed) & & .030 \\
& $\mathrm{~N}$ & 181 & 150 \\
Instagram Use & Pearson Correlation & $.178^{*}$ & 1 \\
& Sig. (2 tailed) & .030 & 150 \\
& $\mathrm{~N}$ & 150 & \\
\hline
\end{tabular}

* Correlation is significant at the .05 level (2-tailed).

As shown in Table 15 and Table 16, there was a positive correlation between anxiety $(M=4.98, S D=3.92)$ and Instagram use ( $M=2.31, S D=2.53), r=.178, p=\leq .05, n=150$.

Table 17. Descriptive Statistics - Anxiety and YouTube Use (Hours per Day)

\begin{tabular}{cccc}
\hline Variables & Mean & Std. Deviation & $N$ \\
\hline Anxiety & 4.98 & 3.92 & 181 \\
YouTube Use & 2.78 & 2.57 & 110
\end{tabular}

Table 18. Relationship Between Anxiety and YouTube Use (Hours per Day)

\begin{tabular}{cccc}
\hline Variables & Statistic & Anxiety & YouTube Use \\
\hline Anxiety & Pearson Correlation & 1 & $.241^{*}$ \\
& Sig. (2 tailed) & & .011 \\
& $\mathrm{~N}$ & 181 & 110 \\
YouTube Use & Pearson Correlation & $.241^{*}$ & 1 \\
& Sig. (2 tailed) & .011 & 110 \\
& $\mathrm{~N}$ & 110 & \\
\hline
\end{tabular}

* Correlation is significant at the .05 level (2-tailed).

As shown in Table 17 and Table 18 , there was a positive correlation between anxiety $(M=4.98, S D=3.92)$ and YouTube use $(M=2.78, S D=2.57), r=.241, p=\leq .05, n=110$.

Table 19. Descriptive Statistics - Stress and Facebook Use (Hours per Day)

\begin{tabular}{cccc}
\hline Variables & Mean & Std. Deviation & $N$ \\
\hline Stress & 6.72 & 4.37 & 181 \\
Facebook Use & 2.12 & 3.06 & 120
\end{tabular}

Table 20. Relationship Between Stress and Facebook Use (Hours per Day)

\begin{tabular}{cccc}
\hline Variables & Statistic & Anxiety & Facebook Use \\
\hline Stress & Pearson Correlation & 1 & $.225^{*}$ \\
& Sig. (2 tailed) & & .014 \\
& $\mathrm{~N}$ & 181 & 120 \\
Facebook Use & Pearson Correlation & $.225^{*}$ & 1 \\
& Sig. (2 tailed) & .014 & 120 \\
& $\mathrm{~N}$ & 120 & \\
\hline
\end{tabular}

* Correlation is significant at the .05 level (2-tailed).

As shown in Table 19 and Table 20, there was a positive correlation between stress $(M=6.72, S D=4.37)$ and Facebook use $(M=2.12, S D=3.06), r=.225, p=\leq .05, n=120$. 
Table 21. Descriptive Statistics - Stress and Instagram Use (Hours per Day)

\begin{tabular}{cccc}
\hline Variables & Mean & Std. Deviation & $N$ \\
\hline Stress & 6.72 & 4.37 & 181 \\
Instagram Use & 2.31 & 2.53 & 150
\end{tabular}

Table 22. Relationship Between Stress and Instagram Use (Hours per Day)

\begin{tabular}{cccc}
\hline Variables & Statistic & Stress & Instagram Use \\
\hline Stress & Pearson Correlation & 1 & $.202^{*}$ \\
& Sig. (2 tailed) & & .013 \\
& $\mathrm{~N}$ & 181 & 150 \\
Instagram Use & Pearson Correlation & $.202^{*}$ & 1 \\
& Sig. (2 tailed) & .013 & \\
& $\mathrm{~N}$ & 150 & 150 \\
\hline
\end{tabular}

* Correlation is significant at the .05 level (2-tailed).

As shown in Table 21 and Table 22, there was a positive correlation between stress $(M=6.72, S D=4.37)$ and Instagram use $(M=2.31, S D=2.53), r=.202, p=\leq .05, n=150$.

Table 23. Descriptive Statistics - Stress and YouTube Use (Hours per Day)

\begin{tabular}{cccc}
\hline Variables & Mean & Std. Deviation & $N$ \\
\hline Stress & 6.72 & 4.37 & 181 \\
YouTube Use & 2.78 & 2.57 & 110 \\
\hline
\end{tabular}

Table 24. Relationship Between Stress and YouTube Use (Hours per Day)

\begin{tabular}{cccc}
\hline Variables & Statistic & Stress & YouTube Use \\
\hline Stress & Pearson Correlation & 1 & $.236^{*}$ \\
& Sig. (2 tailed) & & .013 \\
& $\mathrm{~N}$ & 181 & 110 \\
YouTube Use & Pearson Correlation & $.236^{*}$ & 1 \\
& Sig. (2 tailed) & .013 & 110 \\
& $\mathrm{~N}$ & 110 & 110 \\
\hline
\end{tabular}

* Correlation is significant at the .05 level (2-tailed).

As shown in Table 23 and Table 24, there was a positive correlation between stress $(M=6.72, S D=4.37)$ and YouTube use $(M=2.78, S D=2.57), r=.236, p=\leq .05, n=110$.

Table 25. Descriptive Statistics - Stress and Twitter Use (Hours per Day)

\begin{tabular}{cccc}
\hline Variables & Mean & Std. Deviation & $N$ \\
\hline Stress & 6.72 & 4.37 & 181 \\
Twitter Use & 2.00 & 2.22 & 77
\end{tabular}

Table 26. Relationship Between Stress and Twitter Use (Hours per Day)

\begin{tabular}{cccc}
\hline Variables & Statistic & Stress & Twitter Use \\
\hline Stress & Pearson Correlation & 1 & $.269^{*}$ \\
& Sig. (2 tailed) & & .018 \\
& $\mathrm{~N}$ & 181 & 77 \\
Twitter Use & Pearson Correlation & $.269^{*}$ & 1 \\
& Sig. (2 tailed) & .018 & 77 \\
& $\mathrm{~N}$ & 77 & 77
\end{tabular}

* Correlation is significant at the .05 level (2-tailed). 
As shown in Table 25 and Table 26, there was a positive correlation between stress $(M=6.72, S D=4.37)$ and Twitter use $(M=2.00, S D=2.22), r=.269, p=\leq .05, n=77$.

Table 27. Frequency Data - Social Debt Analysis

\begin{tabular}{cccccc}
\hline & Response & Frequency & Percent & $\begin{array}{c}\text { Valid } \\
\text { Percent }\end{array}$ & $\begin{array}{c}\text { Cumulative } \\
\text { Percent }\end{array}$ \\
\hline Valid & Yes & 36 & 19.9 & 20.3 & 20.3 \\
& No & 141 & 77.9 & 79.7 & 100.0 \\
& Total & 177 & 97.8 & 100.0 & \\
Missing & System & 4 & 2.2 & & \\
Total & & 181 & 100.0 & &
\end{tabular}

When asked if the online activity of friends/followers influence how active one needs to be, $77.9 \%$ of participants responded no that other people's activity (e.g., amount of posts made by a friend/follower and a friend/follower liking one's posts) did not influence their online behavior. The participants reported no motivation to reciprocate supportive behavior of their friends/followers.

There was no correlation between the DASS-21 findings and Snapchat and Pinterest use. Also, there was no correlation between the DASS-21 findings and classification, ethnicity, major, and reported sex. The data did show that there was no statistical difference in the use of social media platforms by reported sex except for Snapchat. The data shows that females $(M=3.24, S D=3.32)$ use Snapchat statistically more hours in day than males $(M=1.69, \mathrm{SD}=1.74)$.

\section{Discussion}

The results of this study suggested a number of interesting findings. Based on when this study was conducted and the number of participants that completed the survey, it was assumed that the depression, anxiety, and stress levels would be in the normal range. This was not the case. Anxiety scores were elevated. When focusing on social media, the data suggest a significant positive correlation between the hours of social media use with depression, anxiety, and stress. The three most popular social media sites as ranked by the participants of this study were, 1) Snapchat, 2) Instagram, and 3) Facebook. Instagram, Facebook, and YouTube use had a significant relationship with depression, anxiety, and stress, but no significant correlations were found with Snapchat and Pinterest. Twitter had a significant relationship with stress, but not with anxiety and depression.

Social debt was also looked at and the data suggested that this was not an issue with the participants. In other words, the number of friends, followers, and contacts or the amount of activity others had on their social media sites had minimal to no influence on the participants" social media usage. This led us to see "social" media not as "social," but rather "my" media. Social media sites that speak to one's ego (their sense of self) has a significant relationship with one's level of depression, anxiety, and stress (e.g., Facebook and Instagram). Although Snapchat is the most popular and used the most by the participants, it is not focused on "likes," unlike Instagram and Facebook. Being "liked" appeared very important from an emotional perspective, but did not influence their need to reciprocate the "likes" to others.

The findings from this study support social comparison theory, where our participants appear at least in part to put a lot of emotional weight on how they are perceived by others. Interestingly, the self-concept that they place on themselves by the feedback they receive may not even be by those that they would consider friends or acquaintances. When the findings from this study is also compared to that of the study titled Social Media and Loneliness (Halston, et al., 2019), we find that social media keeps people superficially connected, but their level of social connectedness is typically not deep and meaningful enough to make people feel emotionally connected to others. Instead, the findings from this study suggest that depressive symptoms, anxiety, and stress are more likely to occur due to social comparison theory combined with the lack of deep and meaningful social connections using social media platforms.

The results of this study suggest the potential adverse effects certain types of social media applications have on the emotional well-being of higher education students. Although professors may not have direct influence on their students' social media usage, this study informs them of this phenomenon. It appears that higher education students attend class increasingly distracted and this study speaks to one possible contributor of this observation.

Limitations to this study includes not having a more diverse student population from various institutions across the nation and the data collected regarding social media usage was self-reported, so other confounding variables could have influenced the participants' perception of their usage. 
Future research should look at social connectedness and how social media platforms can assist with the development of deep and meaningful interactions between people. Also, the relationship between social media and egocentrism should be researched further to see how ego-focused curriculum design in classrooms can be developed to increase student engagement and academic performance.

\section{References}

Abbott, J. (2017). Introduction: Assessing the social and political impact of the internet and new social media in Asia. Journal of Contemporary Asia, 43(4), 579-590.

Aalbers, G., McNally, R. J., Heeren, A., de Wit, S. \& Fried, E. I. (2018). Social media and depression symptoms: A network perspective. Journal of Experimental Psychology: General, 148(8), 1454-1462.

Alahmar, A. T. (2016). The impact of social media on the academic performance of second year medical students at College of Medicine, University of Babylon, Iraq. Journal of Medical \& Allied Sciences, 6(2), 77-83.

Chang, Y. (2012). The relationship between maladaptive perfectionism with burnout: Testing mediating effect of emotion-focused coping. Personality and Individual Differences, 53(5), 635-639.

Charoensukmongkol, P. (2018). The impact of social media on social comparison and envy in teenagers: The moderating role of the parent comparing children and in-group competition amoung friends. Journal of Child \& Family Studies, 27(1), 69-79.

Chukwuere, J. E. \& Chukwuere, P. C. (2017). The impact of social media on social lifestyle: A case study of university female students. Gender \& Behaviour, 15(4), 9966-9981.

Drouin, M., Reining, L., Flanagan, M., Carpenter, M. \& Toscos, T. (2018). College students in distress: Can social media be a source of social support? College Student Journal, 52(4), 494-504.

Fleck, J. \& Johnson-Migalski, L. (2015). The impact of social media on personal and professional lives: An Adlerian perspective. Journal of Individual Psychology, 71(2), 135-142.

Garett, R., Liu, S. \& Young, S. D. (2017). A longitudinal analysis of stress among incoming college freshmen. Journal of American College Health, 65(5), 331-338.

Hales, D. (2009). An invitation to health (13th ed.). Belmont, CA: Wadsworth/Cengage Learning.

Halston, A., Iwamoto, D., Junker, M. \& Chun, H. (2019). Social media and loneliness. International Journal of Psychological Studies, 11(3), 27-38.

Iwamoto, D., Chun, H. (2019). Stress, anxiety and depression: An analysis of higher education students. International Journal of Humanities and Social Science Invention, 8(3), 47-52.

Ley, B., Ogonowski, C., Hess, J., Reichling, T., Wan, L. \& Wulf, V. (2014). Impacts of new technologies on media usage and social behavior in domestic environments. Behaviour \& Information Technology, 33(8), 815-828.

Osman, A., Wong, J. L., Bagge, C. L., Freedenthal, S., Gutierrez, P. M. \& Lozano, G. (2012). The depression anxiety stress scales-21 (DASS-21): Further examination of dimensions, scale reliability, and correlates. Journal of Clinical Psychology, 68(12), 1322-1338.

Rad, A. A., Jalali, M. S. \& Rahmandad, H. (2018). How exposure to different opinions impacts the life cycle of social media. Annals of Operations Research, 268(1/2), 63-91.

Santee, R. G. (2013). The tao of stress: How to calm, balance, and simplify your life. Oakland, CA: New Harbinger Publications, Inc.

Sriwilai, K. \& Charoensukmongkol, P. (2016). Face it, don't Facebook it: Impacts of social media addiction on mindfulness, coping strategies and the consequence on emotional exhaustion. Stress \& Health: Journal of the International Society for the Investigation of Stress, 32(4), 427-434.

Tang, F., Wang, X. \& Norman, C. S. (2013). An investigation of the impact of media capabilities and extraversion on social presence and user satisfaction. Behaviour \& Information Technology, 32(10), 1060-1073.

Weng, L. \& Menczer, F. (2015). Topicality and impact in social media: Diverse messages, focused messengers. Plos ONE, 10(2), 1-17.

Yerkes, R. M. \& Dodson J. D. (1908). The relation of strength of stimulus to rapidity of habit-formation. Journal of Comparative Neurology and Psychology, 18, 459-482.

Zareen, N., Karim, N. \& Khan, U. A. (2016). Psycho-emotional impact of social media emojis. Isra Medical Journal, 8(4), 257-262. 